\title{
Fidelização econômico-torcedora e laços de vinculação com o clube: uma análise dos programas sócio-torcedor cariocas
}

\author{
Economic-fan Loyalty and Links with the Club: \\ an Analysis of the Partner Programs of Rio de Janeiro
}

\author{
Jimmy Medeiros \\ Fundação Getúlio Vargas, Rio de Janeiro/Brasil \\ Doutor em Políticas Públicas, Estratégia e Desenvolvimento, UFRJ \\ E-mail: jimmy.medeiros@fgv.br \\ Philippe Guedon \\ Fundação Getúlio Vargas, Rio de Janeiro/Brasil \\ Doutorando em História, Política e Bens Culturais, CPDOC/FGV
}

\begin{abstract}
RESUMO: As formas de torcer podem ser manifestadas por meio de diversas atitudes, assim como através de distintos laços com o clube. Em meio ao atual projeto modernizador do futebol verifica-se a tendência a elitização dos estádios, elevação do valor do ingresso e conversão do torcedor em espectador ou consumidor. Uma das faces desse projeto é o mecanismo de fidelização torcedora: os programas de sóciotorcedor. Essa fidelização, de modo específico, é um fenômeno que responde a diversas motivações, racionais ou não. Assim, o objetivo do artigo é compreender os motivadores para a adesão, suas vantagens e desvantagens. Mais ainda, é pretendido avaliar diferenças no torcer e no relacionamento com outros indivíduos e grupos. 0 foco pesquisado são os programas atuais dos quatro grandes clubes de futebol do Rio de Janeiro. Metodologicamente, o trabalho conta com entrevistas qualitativas e análise dos discursos oficiais dos clubes e movimentos para a associação.
\end{abstract}

PalaVRaS-Chave: Futebol; Sócio-torcedor; Modernização; Torcidas.

ABSTRACT: Ways of cheering can be expressed through various attitudes, as well as through different ties to the club. In the midst of the current football modernization project, there is a tendency to elitize the stadiums, increase the value of the ticket and convert the fans into spectators or consumers. One of the faces of this project is the fanning loyalty mechanism: the supporter partner programs. This loyalty, in a specific way, is a phenomenon that responds to several motivations, rational or not. Thus, the purpose of the article is to understand the motivators for membership, its advantages and disadvantages. Moreover, it is intended to assess differences in twisting and relationship with other individuals and groups. The focus researched are the current programs of the four major football clubs in Rio de Janeiro. Methodologically, the work counts on qualitative interviews and analysis of the official speeches of the clubs and movements for the association.

KEYwoRdS: Football; Support Partner Programs; Modernization; Supporters. 


\section{INTRODUÇÃo}

As formas de torcer podem ser manifestadas e realizadas por meio de diversas atitudes, assim como através de distintos laços com o clube. Até meados do século anterior, existia uma certa simplificação analítica pela falsa dualização do objeto: a participação torcedora poderia ser expressa através do ingresso em uma torcida organizada, ou por fazer parte do chamado "povão", adentrando as arquibancadas dos estádios sem ser membro dos movimentos torcedores.

Um objeto bastante problematizado no meio acadêmico é a emergência das torcidas jovens, assim como os seus dilemas, conflitos e representações. Esse agrupamento recebeu destaque pelas inovações nas arquibancadas. ${ }^{1}$

$\mathrm{Na}$ atualidade, destacada por uma conjuntura pós-moderna e fluida em que sobressai uma ampliação da mercantilização das relações em nossa sociedade, emergem novas questões nos padrões associativos dos torcedores com seus clubes futebolísticos. Por exemplo, uma série de demandas estão presentes no debate atual, como os movimentos torcedores tidos como não violentos e caracterizados pelo seu apoio incondicional ao clube, independente do resultado ou das condições do time. Ao mesmo tempo, a participação feminina nas torcidas organizadas recebe mais atenção e tem enriquecido o debate na agenda pública. ${ }^{2}$

Ademais, o projeto "modernizador" do futebol tem implicado em várias mudanças no meio futebolístico, como a elitização dos estádios, a transformação desses equipamentos esportivos em arenas, a elevação do valor do ingresso, a priorização dos horários dos jogos às necessidades e interesses da empresa televisiva patrocinadora, as transformações arquitetônicas para promover maior assepsia, como cadeiras numeradas, escalonamento mais íngreme dos degraus,

\footnotetext{
${ }^{1}$ HOLLANDA; MEDEIROS. Do "Colosso do Derby" a Arena Maracanã: a cidade, o estádio e as percepções dos torcedores de futebol sobre a Copa do Mundo 2014, 2014. MURAD. Para entender a violência no futebol, 2012.

2 MENEZES. Entre a fúria e a loucura: análise de duas formas de torcer pelo Botafogo de Futebol e Regatas, 2017. LIMA LOPES; PIMENTA. \#MULHERESNOFUTEBOL: transitividade e avaliatividade na identificação de padrões sexistas, 2017. TEIXEIRA. Futebol, emoção e sociabilidade: narrativas de fundadores e lideranças dos movimentos populares de torcedores no Rio de Janeiro, 2013.
} 
barras de ferros entre os degraus das arquibancadas de maneira a atrapalhar a festa realizada pelos membros e torcidas organizadas, entre outros aspectos. ${ }^{3}$

Neste sentido, se de um lado há barreiras impostas aos tradicionais torcedores populares - ou mesmo a exclusão deles, por exemplo no caso dos geraldinos, logo após o fim do setor "geral" no estádio do Maracanã - de outro há a inclusão de novos tipos de torcedores. Aqueles que, segundo Hollanda e Medeiros, demandam mais conforto, mais segurança e mais requintes.

A Copa do Mundo Fifa 2014 e a Copa das Confederações Fifa 2013 são elementos responsáveis por essa transformação, sobretudo, por acelerarem o processo de modernização do futebol brasileiro. Os principais aspectos evidentes são a construção das novas arenas, assim como a adaptação de antigos estádios a uma conformação imposta pela instituição máxima do futebol. Em meio a todos esses elementos, por conseguinte, o torcedor foi transformado em um espectador ou, mais ainda, ele foi convertido em consumidor. Na contemporaneidade, ao cabo, a ida ao estádio passou a ser planejada, por grande parte dos clubes de futebol da série A do campeonato brasileiro, como uma experiência torcedora. Ou seja, uma série de microeventos são previstos e oferecidos aos ingressantes das arenas para maximizar o seu consumo e, por conseguinte, a sua satisfação. ${ }^{4}$

Embora parte do ethos torcedor permaneça constante - por exemplo, vários dos seus mecanismos de sociabilidade, suas representações simbólicas e atrelamentos territoriais - outros são adaptados à realidade atual. Ao mesmo tempo, uma série de rituais e laços sociais e econômicos emergem pelo interesse, bem como pela necessidade, de manutenção do seu vínculo com o clube torcedor. 0 ingresso passou a ser mais caro, os interiores dos estádios oferecem uma diversidade de lanchonetes e opções de alimentos e bebidas, música ambiente, locutor animando o público presente, além de eventos culturais ocorrerem antes de a bola rolar de maneira a estimular a entrada cada vez mais antecipada.

Uma modalidade desta nova realidade no meio futebolístico brasileiro, e objeto deste trabalho, é o mecanismo de fidelização torcedora, conhecidos como

\footnotetext{
${ }^{3}$ HOLLANDA; MEDEIROS. Do "Colosso do Derby" a Arena Maracanã, 2014. PRIETO; VIANA. No templo do futebol, a privatização da vida cotidiana: da festa para a elitização na cidade do espetáculo, 2014.

${ }^{4}$ TOLEDO, Torcidas organizadas de futebol, 1996.
} 
programa "sócio"-torcedor (PST). Esta modalidade de vinculação de indivíduos à uma instituição amada e admirada, mediante o pagamento contínuo e periódico de valores, tem sido bastante receptiva, considerando a quantidade de pessoas que aderiram. Assim, essa configuração se torna um negócio rentável para alguns clubes, sendo inserida no atual contexto de transformação do futebol.

De acordo com o "Movimento por um futebol melhor",5 existem no país 1.304.507 pessoas vinculadas a 73 clubes com programas de sócio-torcedor. De modo ilustrativo, seis clubes possuem mais de 100 mil torcedores, todavia, nenhum estádio brasileiro tem a capacidade próxima a esta quantidade. Assim, e por mais espantoso que pareça, existem programas de fidelização que não garantem a aquisição de ingresso para todos os jogos, uma vez que alguns destes mecanismos possuem mais torcedores fidelizados que a capacidade dos estádios em que seus clubes jogam.

Para além disso, o curioso é que a transferência de recursos financeiros dos torcedores para o clube de forma periódica nem sempre configura benefícios concretos para o torcedor fidelizado. Afinal, nem sempre o pagamento de valores equivale ao direito de ingressar no estádio no dia que o clube joga como mandante, ao recebimento de uma camisa ou outro material esportivo oficial. Enfim, a dívida contraída - em alguns casos, o torcedor contrata um plano anual de fidelização - não representa, necessariamente, uma utilidade, uma vez que não há previsibilidade de gozar deste privilégio ao longo da "temporada". Até nos casos em que o plano garanta o ingresso para os jogos, a concretização dessa ação depende de múltiplos fatores, como o desempenho esportivo da equipe, o horário dos jogos, assim como a ocorrência de infortúnios.

Outro aspecto importante é que os indivíduos fidelizados como "sóciostorcedores" não se enquadram como os tradicionais sócios-proprietários dos clubes de futebol. Eles não votam nas eleições, nem frequentam as instalações dos clubes. Todavia, possuem uma identificação com o emblema do clube e o seu nome inscrito, diferenciando dos demais torcedores não fidelizados.

\footnotetext{
${ }^{5}$ Mais informações em http://www.futebolmelhor.com.br.
} 
Dessa forma, na prática, a vinculação do torcedor ao clube ocorre por outros motivos e interesses que vão além do retorno de benefícios ou por uma escolha tida como racional. A escolha por esse tipo de laço vai além da satisfação de uma relação econômica. Conforme Santana (2016), a relação está permeada entre o coração e o bolso, ou melhor, entre a razão e a emoção. Assim, o objetivo do presente trabalho é compreender os motivadores para a adesão à um programa sócio-torcedor, contemporizando com o contexto da adesão e de possíveis cancelamentos. Mais ainda, é pretendido avaliar diferenças no torcer e no relacionamento com outros indivíduos e grupos das arquibancadas, como os torcedores organizados e os torcedores não fidelizados, de maneira a compreender distinções a respeito do envolvimento com o clube. Ao mesmo tempo, mapear os argumentos a respeito das possíveis vantagens e desvantagens deste tipo de relacionamento com o clube.

Para isso, o trabalho conta com entrevistas para observar e avaliar como emergem os discursos a respeito desses temas, durante o trabalho de campo. 0 foco pesquisado são os programas atuais dos quatro grandes clubes de futebol da cidade do Rio de Janeiro: Botafogo de Futebol e Regatas, Clube de Regatas Flamengo, Fluminense Football Club e o Clube de Regatas Vasco da Gama. Nesse sentido, o presente trabalho busca compreender mais uma faceta dentre as múltiplas existentes da relação entre o torcedor e o seu clube de futebol.

\section{OS QUATRO PROGRAMAS SÓCIO-TORCEDOR (PST) PESQUISADOS}

Antes de abordar o conteúdo das entrevistas com torcedores filiados aos atuais PST dos quatro grandes clubes de futebol da capital carioca, apresentaremos algumas características mais evidentes. Para acessar os sítios na internet dos programas selecionados, em um primeiro momento, ingressamos no portal "Movimento por um futebol melhor", que reúne os diversos PSTs dos principais clubes de todo o Brasil. A título de ilustração, o portal informa concentrar 1.340 .447 sócios-torcedores de 73 agremiações clubísticas, perfazendo uma média equivalente a 18.362.

A página inicial do portal do "Movimento por um futebol melhor" de forma explícita evidencia a nova relação estabelecida entre clubes e seus torcedores: o torcedor passou a ser um consumidor-espectador. Um dado que sustenta este 
argumento é a imagem que estampa a tela inteira, uma vez que ela representa o torcedor como um consumidor. Afinal, conforme a figura 1, o homem trajando uma camisa branca com o número 10 nas costas - numeral simbólico para o futebol está com a bola sob o braço e olhando para gôndolas de um mercado.

A informação seguinte do portal é o "Torcedômetro Futebol Melhor", um ranking dos clubes, conforme a quantidade de torcedores vinculados aos seus programas sócio-torcedor. Este é um mecanismo para estimular competição ou concorrência clubística de maneira a sensibilizar o torcedor para se engajar e impulsionar o seu clube para um escalada de sucesso.

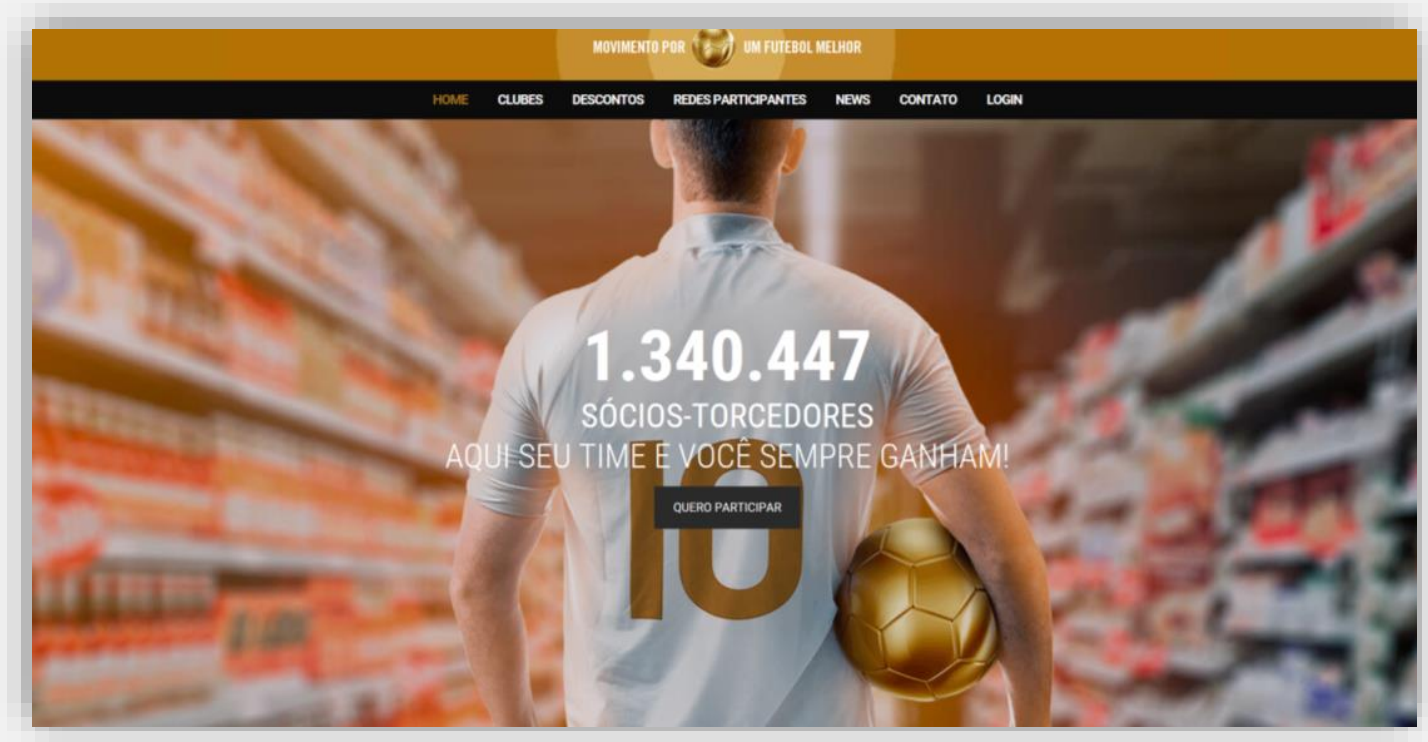

Fig. 1 - Tela principal do portal "Movimento por um futebol melhor" Fonte: https://www.futebolmelhor.com.br.

No site, em seguida, são evidenciadas algumas das principais vantagens econômicas e desconto em produtos esportivos e serviços. Estes, apresentados em imagens grandes são fortemente associados ao "mundo" do torcedor masculino de futebol: cerveja, esporte, carro e supermercado (como cerveja e outros mais). ${ }^{6}$

Ademais, o próprio site apresenta o "movimento" como uma "união de torcedores, clubes e grandes empresas que acreditam que o nosso futebol tem um potencial gigante para se desenvolver mais", portanto, consideram para isso, a participação essencial e inovadora do terceiro elemento: as grandes empresas. A

${ }^{6}$ LYSARO-DIAS. A construção e desconstrução de estereótipos pela publicidade brasileira. 
respeito disso, pode ser considerada inovadora, pois antes desta iniciativa nunca ocorreu um engajamento destes agentes de forma tão expressiva neste setor esportivo. Além disso, um pouco mais adiante, o portal apresenta seus argumentos para estimular a fidelização econômico-torcedora, pois o "movimento" vai "ajudar a fazer tudo o que o país do futebol sempre mereceu".

Para entrar nesse Movimento, tem que ter amor à camisa. Mas também ao "bolso". Ou seja, esta iniciativa vai retribuir o futebol nacional com um projeto econômico-financeiro que tornará as equipes ainda mais "fortes" e para isso conta com a adesão do torcedor - transmutado em consumidor-espectador - que "ama" seu clube e o próprio "bolso". Este último aspecto parece um contrassenso, uma vez que o torcedor firmará um contrato para garantir um fluxo de dinheiro da sua conta corrente para a do clube do coração. Todavia, o "movimento" anuncia uma série de descontos e vantagens financeiras em produtos e serviços superiores ao valor pago ao clube. Assim, aparentemente, o sócio-torcedor teria uma dupla vantagem ao, em tese, ajudar seu clube do coração e, ao mesmo tempo, obter vantagem econômica para si.

Em seguida, visitamos os sites de cada PST para identificar características gerais, algumas similaridades, assim como diferenças mais relevantes. ${ }^{7}$ Por exemplo, o programa intitulado "Sou Botafogo", do clube Botafogo Futebol e Regatas, oferece um plano único (com valor mensal de $R \$ 14,90$ ) que pode ser modulado, conforme o interesse do torcedor em nove opções adicionais, seis delas são pacotes de ingressos para toda a temporada do clube em jogos de futebol no seu estádio, diferindo a localização da arquibancada ou camarote e, ao mesmo tempo, o preço cobrado. Para o ano de 2018 , os valores oscilam entre $\mathrm{R} \$ 100,00$ e $\mathrm{R} \$ 420,00$. As três opções restantes remetem à aquisição de desconto no valor do ingresso para qualquer jogo da temporada (plano por $\mathrm{R} \$ 15,00 /$ mensal), pacote de estacionamento para o ano de 2018 (plano por $\mathrm{R} \$ 150,00 /$ ano) e até a oferta

\footnotetext{
${ }^{7}$ Cabe apontar uma falha grave do funcionamento de adesão aos programas através do portal pesquisado. Por exemplo, ao clicar em "Quero participar" o visitante teria a opção de selecionar um clube para, em seguida, conseguir acessar a página própria do programa sócio-torcedor desejado em uma nova aba do navegador. Apesar desta suposta facilidade, somente foi possível ingressar à página de um clube do Rio de Janeiro. Para os outros três casos apareceu uma informação de erro - "Link interrompido" - evidenciando uma barreira adicional. O ingresso ao site do clube só ocorreu após realizar a busca em páginas especializadas nesta finalidade.
} 
inovadora de ingressos para assistir à temporada 2018/2019 da equipe de basquete do clube (plano por R $\$ 120,00 / a n o)$.

O Clube de Regatas Vasco da Gama oferece o programa "Gigante” composto por sete opções de planos mensais. Os valores oscilam entre $\mathrm{R} \$ 14,98$ e $\mathrm{R} \$ 169,98$, sendo que apenas os três planos mais caros oferecem ingressos para todos os jogos do clube no ano como mandante. Ademais, os dois planos mais baratos oferecem apenas um ingresso na temporada, sendo um plano direcionado ao torcedor residente fora do estado do Rio de Janeiro. É tido como uma forma de fidelizar parte da sua torcida de outros estados, angariando recursos econômicos. Cabe mencionar que outros dois planos oferecem apenas desconto no valor o ingresso, quando da sua aquisição pela internet ou no guichê.

O Fluminense Football Club possui o programa "Sócio Futebol" contendo cinco opções de planos de ST. Os valores oscilam de $\mathrm{R} \$ 9,90$ a $\mathrm{R} \$ 191,40$ por mês, sendo que os dois planos mais caros oferecem ingressos para todos os jogos do ano, quando o clube for mandante, e possibilita voto para presidente, logo após manter a fidelização por um ou dois anos consecutivos, dependendo da opção escolhida. Por outro lado, os dois planos mais baratos oferecem apenas promoções ocasionais, sendo direcionado ao torcedor residente fora do estado do Rio de Janeiro e crianças. Um outro plano cobra $\mathrm{R} \$ 35,00$ por mês e oferece $50 \%$ de desconto no valor de aquisição do ingresso que dependendo da frequência ao estádio que o associado tiver não configura uma vantagem econômica. A opção mais barata é destinada aos torcedores mirins.

O Clube de Regatas Flamengo, em seu programa "Nação Rubro-Negra", oferta oito opções de planos aos seus torcedores. Os valores oscilam entre $\mathrm{R} \$ 18,00$ e R $\$ 199,00$ mensais, oferecendo apenas "prioridade na compra do ingresso". Portanto, difere dos demais clubes grandes da cidade. Afinal, neste caso, não há a aquisição do ingresso para os torcedores fidelizados economicamente. Dentre as opções disponíveis pelo site, um plano é indicado para crianças com idade de até 14 anos, em que o torcedor recebe uma "carteirinha e experiências". Assim como no PST vascaíno e tricolor, há um plano destinado exclusivamente para os torcedores residentes fora do estado do Rio de Janeiro. Os demais planos oferecem desconto para a aquisição de ingresso ao longo da temporada e, dependendo da opção 
desejada, permite comprar de um a seis tickets de entrada. Interessante informar que alguns planos podem ser compartilhados por até quatro pessoas.

Em uma perspectiva geral dos quatro programas analisados, conforme dados na tabela 1, o valor mínimo cobrado pelos clubes é bem parecido, tendo uma diferença próxima a $\mathrm{R} \$ 8,10$. Por outro lado, o valor teto dos planos oferecidos tem uma discrepância de até $\mathrm{R} \$ 132,33$ mensais e, qualitativamente, o plano mais caro do Botafogo permite acesso aos jogos em que é o clube mandante, porém na opção mais cara do Flamengo há a possibilidade prioritária de adquirir até seis entradas com desconto.

Em geral, os torcedores podem escolher planos de fidelização com ou sem a opção de ter a entrada para os jogos de mando do seu clube, exceto o Flamengo. E isto é espantoso, pois o clube cobra os valores mais altos e oferece os menores benefícios. Provavelmente isto se reflete na quantidade de torcedores fidelizados, afinal, o clube possui quantidade muito próxima dos clubes rivais, sendo que metade da população fluminense se autodeclara torcedor desse clube, ${ }^{8}$ ou seja, possui o mercado potencial superior aos demais. Assim, o total de filiados fica aquém do que poderia alcançar, sobretudo se comparado aos valores obtidos por equipes com mais de 100 mil filiados, como o Sport Club Internacional, Grêmio Foot-Ball Porto Alegrense, o Sociedade Esportiva Palmeiras e o São Paulo Futebol Clube.

Além disso, todos os planos dos quatro clubes garantem os mesmos descontos apresentados no portal "Movimento Futebol Melhor", assim como na loja oficial do clube, o envio de uma carteirinha personalizada de torcedor fidelizado, assim como a possibilidade de participar de "experiências exclusivas", como conhecer os bastidores do clube, do estádio, por exemplo. Neste sentido, o modelo de negócio é bastante similar e busca atender as necessidades e demandas do torcedor modelo do futebol moderno. ${ }^{9}$

8 Fonte: http://globoesporte.globo.com/futebol/noticia/2014/08/pesquisa-mostra-torcida-do-flacom-grande-vantagem-sobre-rivais-no-rio.html.

${ }_{9}$ PRIETRO; VIANA. No templo do futebol, a privatização da vida cotidiana: da festa para a elitização na cidade do espetáculo. 


\begin{tabular}{|c|c|c|c|c|}
\hline & Vasco & Botafogo & Flamengo & Fluminense \\
\hline Filiados & 28.435 & 36.694 & $\begin{array}{c}31.206 \\
(101.468)\end{array}$ & 38.815 \\
\hline Opções de plano & 7 & $1(+9)$ & 8 & 5 \\
\hline $\begin{array}{l}\text { Valores } \\
\text { disponíveis } \\
\text { (mensal) }\end{array}$ & $\begin{array}{l}\mathrm{R} \$ 14,98 \mathrm{a} \\
\mathrm{R} \$ 169,98\end{array}$ & $\begin{array}{c}\mathrm{R} \$ 14,90 \mathrm{a} \\
\mathrm{R} \$ 66,67\end{array}$ & $\begin{array}{c}\mathrm{R} \$ 18,00 \mathrm{a} \\
\mathrm{R} \$ 199,00\end{array}$ & $\begin{array}{l}R \$ 9,90 \text { a } \\
R \$ 191,40\end{array}$ \\
\hline O que oferece & $\begin{array}{c}\text { Ingresso ou } \\
\text { desconto no } \\
\text { ingresso. }\end{array}$ & $\begin{array}{l}\text { Ingresso ou } \\
\text { desconto no } \\
\text { ingresso. }\end{array}$ & $\begin{array}{l}\text { Desconto } \\
\text { no } \\
\text { ingresso. }\end{array}$ & $\begin{array}{l}\text { Ingresso ou } \\
\text { desconto no } \\
\text { ingresso. }\end{array}$ \\
\hline
\end{tabular}

\section{RAZÕES PARA A ADESÃO: ENTRE O SENTIMENTO E A RAZÃO}

As entrevistas semiestruturadas foram realizadas com o mesmo roteiro, de maneira a permitir comparação dos argumentos dos diferentes torcedores entrevistados. Nesse sentido, as interações com os sócios-torcedores abordavam, de início, questões a respeito do ano de adesão e da modalidade do plano do PST. A partir disso, buscamos mapear nas falas os motivos da adesão ao Programa de SócioTorcedor. Desta forma, identificamos que a adesão responde a uma vontade multidimensional, que perpassa o simples amor ao clube, a ajuda financeira à instituição e à facilidade na compra de ingressos.

Em nenhuma das entrevistas realizadas, contudo, o entrevistado mencionou apenas uma razão. Por mais que, por vezes, houvesse mais ênfase em determinada razão, sempre esteve acompanhada de outra.

Em uma das entrevistas, N. C. afirmou que aderiu motivada pelo próprio sentimento, dizendo a sua razão não é nada muito tangível. Reforça até que a adesão ao plano Raça, do Flamengo, foi originada a partir da representatividade do nome do plano frente ao grito da torcida do clube. Afirma: "[Aderi] por um motivo quase bobo. Mas é porque tem o grito do Flamengo: Raça, amor e paixão. [...] Acho que o mais barato é o Tradição. Mas, pô, dez reais mais caro... Aí eu fui lá no Raça. Por conta do cartão e do desenho. Era mais bonito [riso]". 
Dessa forma, é possível observar que por mais que exista esforço por parte dos clubes em anunciar vantagens mercadológicas, há razões de adesão que estão no terreno emocional. Além disso, outra arraigada razão para a adesão é o fato de "ajudar o clube". Os clubes cariocas em grave situação financeira utilizam correntemente da convocação dos torcedores como forma de aliviar as contas das agremiações. Entre os cinco clubes mais endividados do Brasil, três deles são cariocas - Botafogo ( $1^{\circ}$ ), Fluminense $\left(3^{\circ}\right)$ e Vasco ( $\left.5^{\circ}\right) .10$

J. S. é adepto do PST do Botafogo, do plano mais básico, que não tem benefícios de ida aos jogos ou acesso ao clube. Segundo ele, a razão principal para a adesão é "ajudar o clube a sair da pindaíba. [Ter] alguma participação". R. G., torcedor do Fluminense, afirma que a única diferenciação dele para os outros torcedores é o fato de que ajuda o clube. Segundo ele, os outros "geralmente só reclamam e não ajudam".

Portanto, existem interesses na adesão que perpassam motivações sentimentais, que incentivam um comportamento de cooperação com o clube. Outras razões, contudo, são originadas de uma ação racional por parte do torcedor na busca de vantagem na compra de ingressos ou descontos.

Segundo A. R., aderente ao PST do Vasco, a principal motivação para a adesão no programa é a praticidade na compra de ingressos, no qual compra de forma online e acessa o estádio por meio de entrada preferencial. 0 seu caso é ainda curioso, uma vez que detém o título de sócio-proprietário e, mesmo assim, decidiu por se associar. Na estrutura associativa do clube, o sócio-proprietário tem possibilidade de participação política, bem como frequentar as sedes do clube. Contudo, o acesso a praças esportivas para assistir aos jogos do clube não constam do plano. 0 sócioestatutário tem regime igual ao não sócio na compra de ingresso; deve comparecer as bilheterias pessoalmente e adquirir sem qualquer desconto.

R. G. afirma que aderiu também pelas vantagens na compra de ingressos. $\mathrm{Na}$ sua situação, afirma que a adesão ao sócio é justificada pela garantia de descontos de pelo menos 50\% na compra de ingressos. Segundo ele, que não é mais estudante,

10 Estudo realizado pela Sports Valeu, divulgado em março de 2018. Disponível em: https://esportes.r7.com/futebol/fotos/veja-quais-sao-os-20-clubes-mais-endividados-do-brasil07052018\#!/foto/10. 
é uma forma de garantir acesso ao clube com valor próximo ao que pagava com os descontos obrigatórios garantidos pela Lei da Meia-entrada. Além disso, reforça que a adesão ao PST faz com que tenha acesso a uma carteirinha de sócio, que permite a entrada direta nos estádios, não necessitando da troca do voucher por ingressos.

Outra vantagem anunciada é a compra antecipada, de forma prioritária. Nos últimos anos, os clubes do Rio tiveram participação efetiva em competições internacionais e os clubes utilizaram o PST como uma forma de garantia de acesso mais facilitado de ingressos aos aderentes. J. S., torcedor do Botafogo, aderiu duas vezes ao programa de sócio: em 2013 e 2015. Segundo ele, a razão para a adesão na segunda vez foi a entrada da equipe na Libertadores e, com isso, a vontade de garantir o acesso aos jogos.

Contudo, essa vantagem não é sempre vista de forma positiva. N. C., torcedora do Flamengo, julga positiva a existência da prioridade se pensar de forma particular, mas diz que tem suas complicações: "Eu acho bom, mas, ao mesmo tempo, eu não gosto. Tem jogos do Flamengo que termina e o pessoal em geral não consegue, que já esgotou o ingresso. Jogos de Libertadores, essas coisas. [O público em geral] é o último da fila".

Argumentamos, portanto, que existem razões de duas grandes ordens para a adesão verificadas nas entrevistas: o sentimento de amor ao clube e as vantagens na compra de ingressos. A primeira, expressa-se na vontade de sentir-se parte do clube e na ajuda financeira; já, a segunda, expressa-se pelos descontos e entradas diferenciadas.

Essas razões são reforçadas pelos clubes quando gestam e divulgam os programas de sócio-torcedor. No entanto, não são as únicas razões anunciadas pelas agremiações para atrair sócios. Os clubes, via de regra, buscam parceiras com empresas privadas para oferecer descontos específicos em produtos para os aderentes.

Apesar disso, não obstante o esforço dos clubes, os sócios-torcedores não usufruem com tamanha intensidade desses benefícios. Isso pode ser justificado pela menor divulgação desses benefícios ou pela ênfase dos usuários apenas nas vantagens relacionadas ao esporte. Sobre essa questão, N. C. diz: "Não usufrui nada porque eu sou meio distraída nessas coisas. Mas volta e meia eles me mandam e- 
mail falando que sócio-torcedor tem desconto na compra de não sei quantas coisas. Mas eu particularmente nunca usufruí porque eu esqueço mesmo".

Apenas dois entrevistados disseram ter usufruído das vantagens de empresas conveniadas. Ambos disseram que fizeram uso apenas uma vez, em descontos em cervejas nos supermercados.

É possível notar, portanto, que não há grande incentivo de adesão por parte das vantagens oferecidas por empresas parceiras. Até mesmo vantagens como descontos em produtos do clube são utilizados com baixa intensidade. Um entrevistado apenas afirmou ter utilizado desconto na loja oficial para a compra de uma camisa do clube. Nesse sentido, reforça-se que a prática de "torcedorconsumidor" ainda é incipiente.

\section{A DIFERENÇA ENTRE OS SÓCIOS-TORCEDORES E OS DEMAIS TORCEDORES}

Questionamos se o pertencimento ao PST faz do entrevistado se sentir diferente dos demais torcedores, incluindo também os torcedores organizados. A maior parte das respostas foi que não sentia diferença entre esses grupos ou entre os sóciostorcedores e qualquer outro.

No entanto, houve algumas menções que refletem sobre essa diferenciação. J. C. e R. G. afirmaram que eles se diferenciavam dos demais torcedores apenas pelo fato de "ajudar o clube". Contudo, J. C. ainda insiste que se vê de forma diferente, mas que isso não se torna uma adjetivação positiva: "Acho que tem uma diferenciação, mas não sei se ela é positiva. É só em condição de ajudar o clube. Em termos de mobilização e acesso, o torcedor organizado frequenta muito mais o clube e os jogos do que eu. É outro tipo de apoio".

N. C. e B. B. reforçam que há uma diferenciação que se dá pela questão econômica, mas que isso não se configura em uma superioridade. Segundo N. C., "não faz diferença. Até porque eu sei que tem uma questão socioeconômica. E só o fato de eu ser sócia-torcedora... Eu não me sinto mais flamenguista por isso". É, em síntese, uma diferenciação de classe entre aqueles que conseguem pagar pelo plano e aqueles que não tem essa possibilidade. Além disso, questionamos por qual razão optaram 
pelo sócio-torcedor e não pelo sócio-estatutário, buscando entender a imagem que é construída em torno dos dois tipos de sócio, além das razões para se associarem.

Conforme já mencionado, A. R. é o único entrevistado que possui os dois planos. Os outros estão entre o desconhecimento dessa natureza de associação, a incapacidade de pagar por ele e a opção deliberada de não associar.

R. G. diz que desconhece como é realizada essa forma de adesão no Fluminense. Diz que a razão geral para aderir a essa modalidade é a participação política, mas que, no caso específico do Fluminense, não é necessária, uma vez que o sócio-torcedor também pode participar, ainda que com algumas restrições. Por isso, não vê razão se para associar.

N. C. afirma que conhece apenas em linhas gerais o que é o sócio-estatutário do Flamengo, mas ainda assim, possui uma imagem construída sobre o programa, que é expressa da seguinte maneira:

Parece uma coisa mais burocrática e também é algo que demanda mais tempo. Assim, eu gosto de futebol, gosto muito do Flamengo, mas o sócio-torcedor eu não acho que demanda muito a minha intenção. Às vezes, quando eu estou com coisas mais atribuladas na vida, eu posso só continuar a vida. Sócio-estatutário me parece aqueles torcedores mais em tempo integral, sabe? [...] Sócioestatutário, vou te dizer, eu nunca nem considerei. Eu nem sei quanto é o valor ou coisa assim.

Além dessa entrevistada, B. B. cogita apenas usufruir dos possíveis benefícios do sócio-torcedor, sem pretensões de participação na vida política do clube. Enxerga, pois, sua participação relacionada somente à arquibancada.

Eu não tenho interesse em frequentar a vida política do clube. Não tenho tempo, nem interesse. Obviamente eu acompanho, mas... E por outro lado também, não é qualquer um que pode ser sócioestatutário do clube. Tem que pagar um valor muito grande, enfim, milhares de reais. [...] Eu não moro perto do clube também, não posso usufruir do clube. [...] Meu interesse é mais no futebol mesmo.

Em suma, é possível notar que os entrevistados possuem uma ideia de que o sócio-estatutário pressupõe uma participação política mais ativa no clube, que consequentemente demandaria tempo e dedicação. Por essa razão, repelem a 
ideia. Além disso, o interesse dos aderentes entrevistados é direcionado apenas para a esfera do futebol, por isso a opção pela não participação nas demais esferas que o clube participa.

\section{OPÇ̃̃o PELA SAÍDA dO PST}

Três entrevistados manifestaram que já saíram do programa de sócio-torcedor em algum momento, mas que voltaram a aderir. R. G. decidiu sair do PST do Fluminense após a saída do jogador Fred, que foi contratado pelo Cruzeiro à época. É um exemplo de que a condução da administração do clube pode incentivar ou não a adesão quanto também a saída. Isso é anunciado por J. S., de forma caricata, mas anunciando o desagravo administrativo como razão para o abandono do PST:

Eu já pensei em cancelar várias vezes, mas acho que isso está ligado ao desempenho do clube. Eu acho que o clube está desorganizado, está uma bagunça e dá uma certa raivinha de estar jogando dinheiro fora. Mas mantenho porque eu sou doente mesmo [riso]. Eu acho que... Bom, tem lugar de fala, não é? Mas eu acho que só botafoguense tem essa consciência de classe, essa vocação para sofrer. Todo botafoguense é expert em zoar o clube, falar mal do clube, identificar todos os problemas e más sortes... Acha que o time está predestinado a fracassar sempre, então a gente continua.

Além desta, outra razão para a saída é a dificuldade financeira. Em momentos de crise econômica os clubes sofrem com as saídas de torcedores dos PSTs, uma vez que podem representar gastos supérfluos frente as necessidades primeiras da vida cotidiana.

N. C. afirma que pensou em cancelar por essa razão, mas tão logo fora convencida de não abandonar: "Única vez que eu considerei cancelar é porque eu estava muito sem dinheiro. Mesmo assim foi uma coisa: 'ah, deixa, são 40 reais'. Até conversei com meus amigos que aderiram junto comigo e eles disseram: “'o quê que é isso? É só 39,90'”.

Nesse ponto, é notável que o investimento no PST não é feito sem uma avaliação da relação "custo-benefício", ainda que ela não seja realiza em termos financeiro-materiais. Há também o benefício de ver o clube bem administrado ou 
mantendo seus ídolos. Diante dessa relação, manter os associados é não só garantir o acesso às vantagens prometidas, mas também gerar incentivos a partir da administração e dos resultados esportivos.

\section{CONSIDERAÇõES FINAIS}

A modernização do futebol é uma tendência no cenário futebolístico brasileiro, cunhada, principalmente, por uma ampla mercantilização dos diversos aspectos desta atividade esportiva. O aumento do valor do ingresso, as modificações arquitetônicas dos estádios para atender a um formato de "arenas", ao modo europeu, além de estabelecer os horários dos jogos para privilegiar a veiculação televisiva, em detrimento do torcedor das arquibancadas, são as facetas mais evidentes. Para além do campo esportivo, esta tendência pode ser verificada em outras esferas da sociedade brasileira, como a ampla mercantilização - e financeirização - dos serviços sociais, como a saúde, a educação, a habitação e a aposentadoria. ${ }^{11}$

No bojo desta transformação há o incremento dos programas sóciotorcedor como uma nova relação entre o clube e o torcedor, gerando benefícios para ambos. Todavia, a adesão ao PST não proporciona um bom "custo-benefício" ao bolso do torcedor. As entrevistas permitem observar que a adesão e a manutenção nos programas de sócio-torcedor são decisões permeadas por explicações multicausais, que confluem vantagens materiais e elementos de ordem emocional. Os sócios-torcedores utilizam das vantagens na compra de ingressos e acesso aos estádios; tanto quanto da narrativa de que ajudam o clube financeiramente. Cabe, portanto, aos clubes terem atenção a esses pontos, ampliando as razões para o ingresso nos PSTs.

Também identificamos um elevado conhecimento, por parte dos torcedores, da existência de descontos em produtos e serviços em empresas conveniadas. Todavia, de modo distinto aos relatos direcionados ao ingresso e à experiência de jogo, esses descontos em produtos e serviços ainda não são

\footnotetext{
${ }^{11}$ FAGNANI. Piso de proteção social: o debate internacional e a experiência brasileira, 2012.
} 
apontados pelos sócios-torcedores como motivador para a sua adesão ao PST. Tampouco são utilizadas de forma mais prática e sistemática pelos entrevistados, muito embora haja um esforço dos clubes, das empresas e do "Movimento por um Futebol Melhor" em utilizar este argumento para convencer seus torcedores.

Importante ressaltar que são consideradas as particularidades de cada clube e dos seus respectivos programas de fidelização. Por exemplo, o Botafogo e o Vasco possuem estádios para mandar seus jogos, diferentemente, do Flamengo e do Fluminense que possuem uma relação conflituosa com a gestora do estádio do Novo Maracanã, criando incertezas e empecilhos para o planejamento anual por parte dos torcedores - que não sabem ao certo o local das partidas - e dos clubes - que precisam modelar seus produtos ao público.

O presente artigo fomenta as discussões sobre fidelização dos torcedores a partir da realidade local dos clubes do Rio de Janeiro e as relações empreendidas entre as agremiações, os programas de sócio e os torcedores aderentes. Em síntese, trata o fenômeno do sócio-torcedor como parte da discussão mais geral de modernização do futebol e das relações que são construídas ao seu redor.

\section{REFERÊNCIAS}

FAGNANI, Eduardo. Piso de proteção social: o debate internacional e a experiência brasileira. Texto para discussão, IE/Unicamp, Campinas, n. 203, 2012.

HOLLANDA, Bernardo Buarque de; MEDEIROS, Jimmy. Do "Colosso do Derby" a Arena do Maracanã?: a cidade, o estádio e as percepções dos torcedores de futebol sobre a Copa do Mundo 2014. Interseções, UERJ, v. 16, p. 328-353, 2014.

LIMA-LOPES, Rodrigo; PIMENTA, Izadora. \#MULHERESNOFUTEBOL: transitividade e avaliatividade na identificação de padrões sexistas. Revista Humanidades \& Inovação. Palmas, v. 4, n. 6, p. 116-131, 2017.

LYSARDO-DIAS, Dylia. A construção e desconstrução de estereótipos pela publicidade brasileira. Stockolm Review of Latin American Studies, n. 2, 2007. MENEZES, Isabella Trindade. Entre a fúria e a loucura: análise de duas formas de torcer pelo Botafogo de Futebol e Regatas. Rio de Janeiro: Editora Multifoco, 2017. 
MURAD, Maurício. Para entender a violência no futebol. Rio de Janeiro: Editora Benvirá, 2012.

PRIETRO, Gustavo; VIANA, Juliana Nazaré Luquez. No templo do futebol, a privatização da vida cotidiana: da festa para a elitização na cidade do espetáculo. In: SANCHÉZ, Fernando; BIENENSTEIN, Glauco; OLIVEIRA, Fabrício Leal de; NOVAIS, Pedro. (Orgs.). A Copa do Mundo e as cidades: políticas, projetos e resistências. São Paulo: Boitempo, 2014.

SANTANA, Thiago José Silva. O clube no coração e/ou no bolso: os processos de mercantilização do torcer a partir de um programa de sócio-torcedor. Dissertação (Mestrado em Educação Física e Lazer), Universidade Federal de Minas Gerais, Belo Horizonte, 2016.

TEIXEIRA, Rosana da Câmara. Futebol, emoção e sociabilidade: narrativas de fundadores e lideranças dos movimentos populares de torcedores no Rio de Janeiro. Esporte e Sociedade. Rio de Janeiro, ano 8, n. 21, março, 2013.

TOLEDO, Luiz Henrique de. Torcidas organizadas de futebol. Campinas: Autores Associados/ANPOCS, 1996. 